\title{
BMJ Open Changes in psychosocial and physical working conditions and psychotropic medication in ageing public sector employees: a record-linkage follow- up study
}

Anne Kouvonen, ${ }^{1,2,3}$ Minna Mänty, ${ }^{4}$ Tea Lallukka, ${ }^{4,5}$ Olli Pietiläinen, ${ }^{4}$ Eero Lahelma, ${ }^{4}$ Ossi Rahkonen ${ }^{4}$

To cite: Kouvonen A, Mänty $M$, Lallukka T, et al. Changes in psychosocial and physical working conditions and psychotropic medication in ageing public sector employees: a record-linkage follow-up study. BMJ Open 2017;7:e015573. doi:10.1136/ bmjopen-2016-015573

- Prepublication history and additional material are available. To view these files please visit the journal online (http://dx.doi org/10.1136/bmjopen-2016015573).

Received 16 December 2016 Revised 24 May 2017 Accepted 1 June 2017

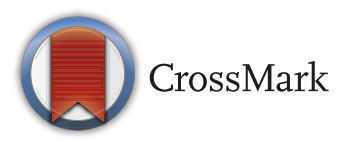

${ }^{1}$ Faculty of Social Sciences, University of Helsinki, Helsinki, Finland

${ }^{2}$ SWPS University of Social Sciences and Humanities in Wroclaw, Wroclaw, Poland ${ }^{3}$ Administrative Data Research Centre (Northern Ireland), Centre for Public Health, Queen's University Belfast, Belfast, UK ${ }^{4}$ Department of Public Health, University of Helsinki, Helsinki, Finland

${ }^{5}$ Finnish Institute of Occupational Health, Helsinki, Finland

Correspondence to Dr Anne Kouvonen; anne. kouvonen@helsinki.fi

\section{ABSTRACT}

Objectives To investigate whether changes in psychosocial and physical working conditions are associated with subsequent psychotropic medication in ageing employees.

Methods Data were from the Helsinki Health Study, a cohort study of Finnish municipal employees, aged 40-60 years at phase 1 (2000-2002). Changes in psychosocial and physical working conditions were measured between phase 1 and phase 2 (2007). Survey data were Iongitudinally linked to data on prescribed, reimbursed psychotropic medication purchases (Anatomical Therapeutic Chemical) obtained from the registers of the Social Insurance Institution of Finland between the phase 2 survey and December 2013 ( $N=3587 ; 80 \%$ women). Outcomes were any psychotropic medication; antidepressants (N06A); anxiolytics (N05B); and sedatives and hypnotics (N05C). Cox regression analyses were performed.

Results During the follow-up, $28 \%$ of the participants were prescribed psychotropic medication. Repeated exposures to low job control, high job demands and high physical work load were associated with an increased risk of subsequent antidepressant and anxiolytic medication. Increased and repeated exposure to high physical work load, increased job control and repeated high job demands were associated with subsequent sedative and hypnotic medication. Age and sex-adjusted HR varied from 1.18 to 1.66. Improvement in job control was associated with a lower risk of anxiolytic, but with a higher risk of sedatives and hypnotic medication. Decreased physical work load was associated with a lower risk of antidepressant and anxiolytic medications.

Conclusion Improvement in working conditions could lower the risk of mental ill-health indicated by psychotropic medication.

\section{INTRODUCTION}

Mental ill-health is a growing concern in working populations. ${ }^{1}$ Adverse working conditions have been proposed as potentially modifiable risk factors for mental ill-health. ${ }^{2}$

\section{Strengths and limitations of this study}

- Unlike previous studies, we were able to examine changes in both psychosocial and physical working conditions.

- Data were derived from a well-characterised occupational cohort, which was deterministically linked to administrative medication records.

- The use of register-based medication data allowed us to remove the prevalent cases and helped avoid the problems related to use of self-report measures such as recall and common method bias.

- Due to relatively long interval between the two working conditions measurements, the study could have underestimated the effect of changing working conditions on subsequent psychotropic medication.

- We did not have information about the clinical indication the examined medication was prescribed for.

Indeed, there is evidence that exposure to adverse psychosocial working conditions including low job control and high job demands are associated with an increased risk of mental ill-health. ${ }^{3-7}$ However, the majority of earlier studies have measured both exposure and outcome using self-reports, which can lead to inflated associations and common method bias. ${ }^{8}$ Other studies have avoided these problems by using register-based outcomes such as psychotropic medication, which is a commonly used marker of mental ill-health in a population. ${ }^{9-14}$

Most of the earlier studies have assessed exposure to adverse working conditions only at one time point, and there is a paucity of large-scale studies examining the association between changes in psychosocial working conditions and mental ill-health. Of a few studies that have separately assessed the 
effects of changes in job control and job demands on mental ill-health, three found that adverse changes in job demands had a stronger effect on the risk of self-reported mental ill-health than adverse changes in job control, whereas positive changes in these domains did not result in improvement in mental health. ${ }^{515} 16$ In a recent study, within-person increase in job control was associated with better self-reported mental health ${ }^{17}$; and in another study, both improvements and deterioration in job demands and job control predicted change in mental health. ${ }^{18}$ However, studies assessing the association between changes in job control and job demands and a more objective measure of mental ill-health, such as recorded psychotropic medication, are lacking.

Moreover, psychosocial working conditions have dominated the discussion about the work-related determinants of poor mental health, even though there is also evidence that physical working conditions are associated with mental ill-health. In the present cohort, increased and repeated exposure to repetitive movements and repeated exposure to awkward postures and rotation of back was associated with an increased likelihood of common mental disorders,${ }^{16}$ desktop work was associated with purchases of sleeping pills among women, ${ }^{19}$ and computer work was a risk factor for disability retirement due to mental causes. ${ }^{20}$ In another study, deteriorating physical working conditions increased perceived mental strain. ${ }^{21} \mathrm{~A}$ review of the impact of working environment on mood disorders discussed the potential mechanisms; however, actual studies conducted in employee cohorts were rare. ${ }^{22}$ In a study among blue-collar workers' exposure to noise intensified anxiety and depression in women. ${ }^{23}$

We set out this study to examine the associations between changes in psychosocial and physical working conditions and subsequent psychotropic medication.

\section{METHODS}

\section{Data}

The data came from the Helsinki Health Study, which is a cohort study designed to investigate social-related and work-related determinants of health and well-being. ${ }^{24}$ The target population was the staff of the City of Helsinki, Finland. Phase 1 questionnaire surveys were collected in 2000, 2001 and 2002 among employees turning 40, $45,50,55$ or 60 each year $(\mathrm{N}=8960$, response rate $67 \%$; $80 \%$ of participants women). Phase 2 survey data were collected in $2007(\mathrm{~N}=7332$, response rate 83\%). Earlier non-response analysis showed that the participants broadly represent the target population. ${ }^{24}$ Survey data were linked to national records using a unique personal identification number for those respondents who had given written consent for the linkage (74\%; $\mathrm{N}=6498)$. Consenting for the data linkage followed a similar pattern as the non-response, except that men provided consent slightly more often than women. ${ }^{24} 25$

In the present study, of those who consented to linkage, only participants who were still employed at phase 2 were included ( $=4207)$. Men, manual workers and those who reported common mental disorders at phase 1 had slightly more often left the employment between the two phases (all $\mathrm{p}$ values $<0.01$, data not shown). Because of the age structure of the cohort, the majority $(86 \%)$ of those who replied at phase 2 and stated that they were not employed had retired.

In addition, we excluded those with purchases of psychotropic medication in 3 months preceding phase 2 ( $\mathrm{n}=337$ for any psychotropic medication). Finally, we excluded those participants who had missing values for any of the study variables $(n=283)$. The exclusions resulted in a final analytic sample of 3587 participants for the analyses examining any psychotropic medication.

\section{Ethics}

The Helsinki Health Study protocol was approved by the Ethics Committees of the Department of Public Health, University of Helsinki, and the health authorities of the City of Helsinki. The study conformed to the principles embodied in the Declaration of Helsinki.

\section{Measurements}

Working conditions

We used a version of Karasek's Job Content Questionnaire ${ }^{26}$ to measure job control and job demands. Job control was assessed by nine and job demands by five items. The job control scale included items measuring skill discretion and decision authority. Job demands items assessed workload and work pace. Missing values were replaced by item modes for those having responded to at least eight job control and four job demands items, respectively. Job control and job demands were both dichotomised at the median. ${ }^{927}$

Physical work load, that is, uncomfortable postures, repetitive trunk rotation, repetitive movements, heavy physical exertion and lifting and carrying heavy loads, was assessed with an 18-item instrument developed at the Finnish Institute of Occupational Health. ${ }^{28}$ Missing values were replaced by item modes for those having responded to at least 14 items. Factor analysis showed that the questions loaded on three factors, of which the first one was interpreted to best measure physical work load. The items with the largest positive standardised scoring coefficients were the following: awkward working positions; rotation of the back; repetitive movements; and heavy physical effort or lifting and carrying heavy loads. Physical work load factor score was dichotomised at the highest quartile. $^{29}$

Changes in psychosocial and physical working conditions were measured by a four-category variable for each of the three exposure variables: (1) repeated low exposure (low exposure at phase 1 and at phase 2); (2) increased exposure (low exposure at phase 1 and high exposure at phase 2); (3) decreased exposure (high exposure at phase 1 and low exposure at phase 2) and (4) repeated high exposure (high exposure at phase 1 and at phase 2). ${ }^{30}$ 


\section{Psychotropic medication}

Data on psychotropic medication were derived from the Finnish Prescription Register. This register is maintained by the Social Insurance Institution and it includes records of all prescribed psychotropic medication purchases reimbursed to Finnish residents in non-institutional settings. For each dispensed drug, the record includes the dispensing date, the WHO Anatomical Therapeutic Chemical (ATC) code, and the quantity prescribed and purchased as the number of defined daily doses. ${ }^{31}$ We extracted information on all purchases of antidepressants, anxiolytics, sedatives and hypnotics (ATC codes N06A, N05B and N05C, respectively; see online supplementary appendix 1) in our analytic sample, following phase 2 survey date (index date) during the follow-up until 31 December 2013. Dates of deaths were retrieved from Statistics Finland (the Causes of Death Register).

\section{Covariates}

All covariates were survey based and from phase 1 . We measured age, sex and marital status (married/cohabiting vs other). Moreover, we measured current smoking (yes vs no), binge drinking (six or more units of alcohol on one occasion once a month or more often), low physical activity (<14 metabolic equivalent hours per week) and body mass index, which was categorised as non-obese $\left(\leq 30 \mathrm{~kg} / \mathrm{m}^{2}\right)$ and obese $\left(>30 \mathrm{~kg} / \mathrm{m}^{2}\right)$.

\section{Statistical analysis}

The associations between sex, age and psychotropic medication during the follow-up were first analysed using the $\mathrm{X}^{2}$ test. Cox proportional hazard models were fitted to examine the association between change in psychosocial and physical working conditions between phase 1 and phase 2 and subsequent psychotropic medication during the follow-up. We estimated HRs and their 95\% CIs for psychotropic medication by changes in each working condition by first controlling for age and sex; then further controlling for marital status, smoking, binge drinking, low physical activity and obesity. In the first analysis, for each working condition, the reference group was the most favourable working condition (ie, repeated high control, repeated low demands and repeated high physical work load, respectively). To examine the effects of positive changes in working conditions, we conducted an additional analysis using the least favourable working condition as the reference group. The follow-up began from the date of the phase 2 survey response and ended at the first record of the psychotropic medication purchase, death, or on 31 December 2013, whichever came first.

We conducted the Therneau-Grambsch non-proportional hazards test, complementing it with the smoothed scatter plot of Schoenfeld residuals against explanatory variables. The visual inspection of the scatter plots supports the interpretation that the proportional hazards assumption was met. The scatter plots for any psychotropic medication are presented in online supplementary appendix 2. Moreover, the interaction terms between
Table 1 Distribution of demographics (phase 1; 20002002), working conditions (phase 1-phase 2; 2007) and any psychotropic medication* between phase 2 and 2013, the Helsinki Health Study, Finland (\%) $(n=3587)$

\begin{tabular}{|c|c|c|c|}
\hline & $\begin{array}{l}\text { No } \\
\text { medication, } \\
\mathrm{n}(\%)\end{array}$ & $\begin{array}{l}\text { Medication, } \\
\text { n (\%) }\end{array}$ & $\begin{array}{l}\text { Mean DDDs } \\
\text { (SD)† }\end{array}$ \\
\hline \multicolumn{4}{|l|}{ Sex } \\
\hline Women & $2034(71)$ & 847 (29) & 496.0 (773.3) \\
\hline Men & $545(77)$ & $161(23)$ & 487.1 (793.0) \\
\hline \multicolumn{4}{|l|}{ Age (years) } \\
\hline 40 & $632(72)$ & 247 (28) & 587.5 (949.9) \\
\hline 45 & $636(68)$ & $298(32)$ & $537.6(788.6)$ \\
\hline 50 & $664(72)$ & $259(28)$ & $429.5(660.0)$ \\
\hline 55 & $627(76)$ & $196(24)$ & $391.2(627.2)$ \\
\hline 60 & $20(71)$ & $8(29)$ & 666.2 (818.6) \\
\hline \multicolumn{4}{|l|}{ Job control } \\
\hline High-high & 1075 (73) & 402 (27) & 453.2 (806.6) \\
\hline High-low & $358(71)$ & $148(29)$ & 458.3 (793.9) \\
\hline Low-high & $300(72)$ & $117(28)$ & 541.5 (761.1) \\
\hline Low-low & $846(71)$ & 341 (29) & $543.1(749.3)$ \\
\hline \multicolumn{4}{|l|}{ Job demands } \\
\hline Low-low & $554(74)$ & $304(26)$ & $411.6(647.4)$ \\
\hline Low-high & $419(72)$ & $165(28)$ & 476.1 (716.0) \\
\hline High-low & $432(72)$ & $169(28)$ & 463.7 (694.2) \\
\hline High-high & $844(70)$ & $370(30)$ & $585.1(915.3)$ \\
\hline \multicolumn{4}{|c|}{$\begin{array}{l}\text { Physical work } \\
\text { load }\end{array}$} \\
\hline Low-low & 1718 (73) & $633(27)$ & $500.2(767.4)$ \\
\hline Low-high & 248 (869) & $112(31)$ & $455.4(679.6)$ \\
\hline High-low & $255(71)$ & $104(29)$ & $428.1(704.8)$ \\
\hline High-high & 358 (69) & 159 (31) & $543.4(909.2)$ \\
\hline
\end{tabular}

${ }^{*}$ Participants with psychotropic medication purchases in 3 months preceding phase 2 were excluded.

†Mean of DDDs and their SDs in those who had psychotropic medication purchases during the follow-up. DDDs, defined daily doses.

each working condition and logarithm of the follow-up period for any psychotropic medication as well as for each medication group were non-significant (all $\mathrm{p}>0.05$ ), further confirming that the proportional hazards assumption was justified.

None of the gender interactions were statistically significant (all interaction terms sex*working condition p>0.05); we therefore analysed women and men together, adjusting for gender.

The analyses were conducted with SAS V.9.4 and R.

\section{RESULTS}

Table 1 shows the distribution of the key study variables by any prescribed psychotropic medication during the 
follow-up. The mean age at baseline was 47.5 years. A total of 1008 participants (28\%) recorded at least one purchase of prescribed psychotropic medication during the mean follow-up of 5.0 years. Psychotropic medication was more prevalent among women (29\%) than among men (23\%). Nineteen per cent of the participants received antidepressant medication during the follow-up. The corresponding figures for anxiolytics and for hypnotics/sedatives were $7 \%$ and $17 \%$, respectively.

As displayed in table 2, after adjustment for age and sex, repeated high job demands (HR=1.22, 95\% CI: 1.04 to 1.42) were associated with any psychotropic medication. The association between repeated high physical work load and any psychotropic medication was marginally statistically significant (HR=1.17, 95\% CI: 0.98 to 1.39 ). Figures 1-3 show survival curves for any psychotropic medication by changes in working conditions.

When the groups of psychotropic medication were examined separately, repeated high job demands (HR=1.20, 95\% CI: 1.00 to 1.45$)$ and repeated high physical work load (HR=1.30, 95\% CI: 1.06 to 1.59$)$ were associated with subsequent antidepressant medication, whereas repeated low job control $(1.37,95 \%$ CI: 1.05 to 1.79), repeated high demands (HR $=1.33,95 \%$ CI: 1.00 to 1.76) and repeated high physical work load ( $\mathrm{HR}=1.66$, 95\% CI: 1.24 to 2.23 ) were associated with subsequent anxiolytic medication. Increased job control and increased physical work load were associated with subsequent sedative and hypnotic medication. Repeated high demands and repeated high physical work load showed associations with subsequent sedative and hypnotic medication. Further adjustment for marital status, health behaviours and obesity only marginally changed the HRs (data not shown).

We additionally tested whether favourable change in working conditions was associated with a lower risk of psychotropic medication, by using the least favourable working conditions as reference categories (table 3). Compared with repeatedly low job control, increased job control was associated with a lower risk of anxiolytic, but a higher risk of sedative and hypnotic medication. Compared with repeatedly high physical work load, decreased physical load was associated with a lower risk of subsequent antidepressant and anxiolytic medication.

\section{DISCUSSION}

In this study, repeated and increased exposure to adverse psychosocial and physical working conditions was associated with subsequent psychotropic medication. It is notable that we found similar associations for both types of working conditions. However, the associations between adverse working conditions and subsequent psychotropic medication were modest. This is expected asthe aetiology of mental disorders - the main indication for psychotropic medication-is complex and multifactorial, involving multiple social, psychological and biological factors. $^{32}$ Exposure to adverse working conditions or a positive or negative change in them is only one such factor.

Compared with employees with repeated low job demands, the employees whose job demands had increased had a higher risk of purchasing any psychotropic medication as well as antidepressant medication. Moreover, repeated exposure to high job demands was associated with subsequent antidepressant and anxiolytic medication, with anxiolytics showing a slightly stronger association. Antidepressant and anxiolytic medications are likely to reflect depression and other mental disorders such as anxiety disorders (including generalised anxiety disorder and panic disorder). A number of previous studies have shown a link between high job demands and an increased risk of mental ill-health. ${ }^{315} 1633$

Previous results for job control have been mixed. In a meta-analytic review published in 2006, low decision latitude predicted common mental disorders. ${ }^{3}$ In terms of more objective outcomes, null results have been reported for psychotropic prescriptions, ${ }^{13} 34$ whereas one previous study showed an association between high decision authority and an elevated risk of hospital admissions due to mental disorders. ${ }^{35}$ In our study, increased job control was associated with a subsequent sedative and hypnotic medication. In a previous study, active jobs, that is, those with high levels of control and demands, were associated with a higher risk of depression and burn-out. ${ }^{36}$ It is possible that increased decision authority and high responsibility may become a burden for some employees. It is also possible that high job control reflects not only working conditions but also characteristics of a generally more active employee with a higher likelihood of seeking treatment. $^{35}$

The result that increased job control was associated with a lower risk of anxiolytic, but a higher risk of sedative and hypnotic medication seems conflicting and is difficult to explain. It is possible that a switch between some anxiolytic benzodiazepine and hypnotic benzodiazepine could confound these associations. Unfortunately we had no information about the indication of the medication use.

When comparing with the least favourable working conditions, increased job control was associated with a lower risk of anxiolytic medication and decreased physical load was associated with a lower risk of antidepressant and anxiolytic medication. Two earlier studies did not find an association between favourable changes in psychosocial working conditions and a decreased risk of subsequent mental ill-health. ${ }^{15}$ However, in one previous study, both improvements and deterioration in job demands and control were associated with corresponding improvements or deterioration in mental health, ${ }^{18}$ and in another study, decrease of job strain was associated with a lower likelihood of repeated insomnia symptoms. ${ }^{38}$

Most of the earlier studies have investigated only psychosocial working conditions. In the present study, repeatedly high and increased physical work load were associated with subsequent psychotropic medication. In 


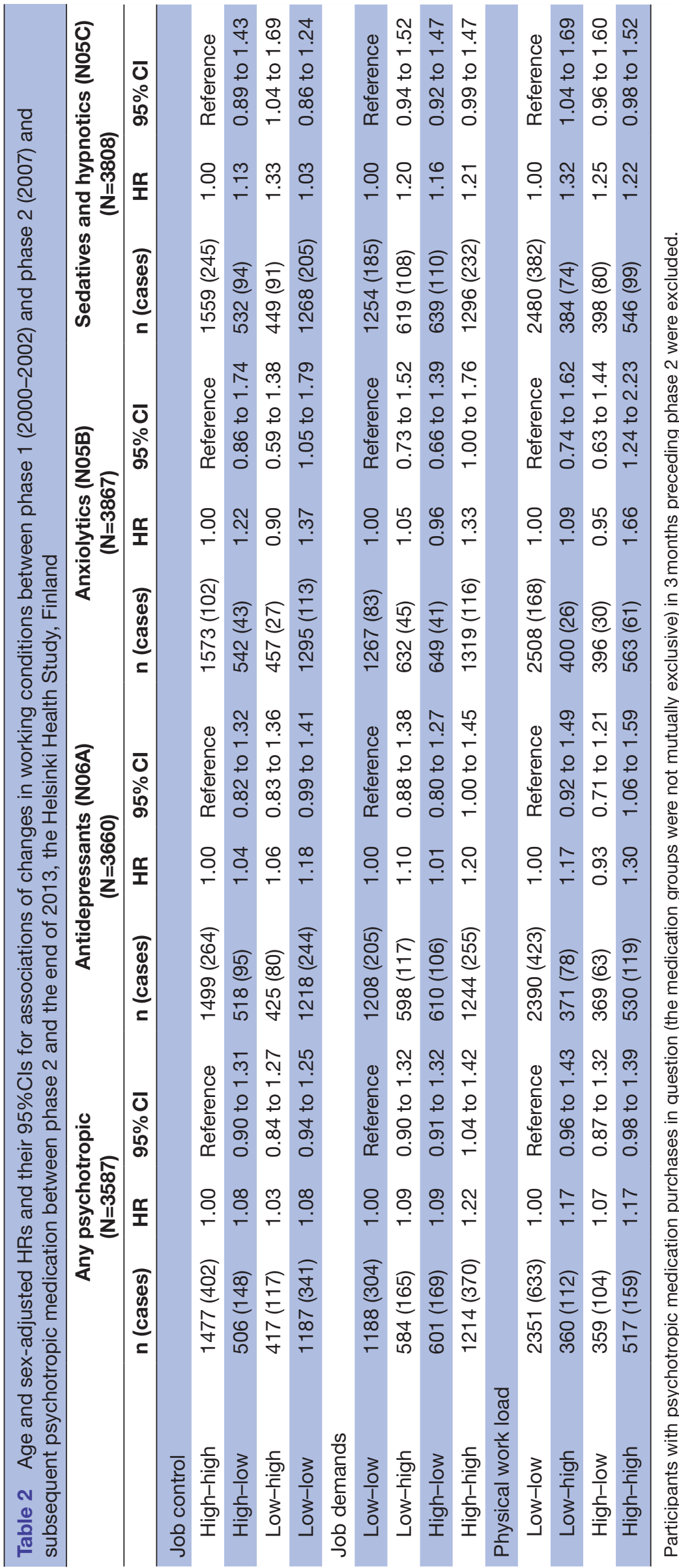




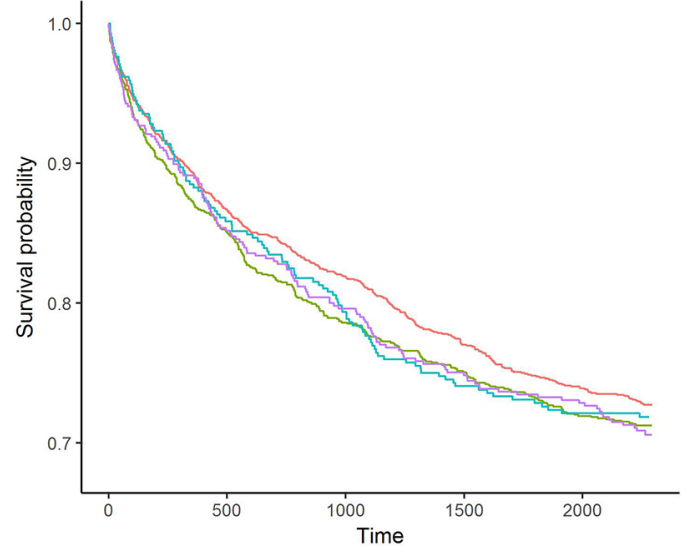

Figure 1 Survival curves for any psychotropic medication by changes in job control.

fact, the strongest association ( $\mathrm{HR}=1.66$ for anxiolytic medication) between working conditions and psychotropic medication was found for repeated high physical workload. Our findings thus support the earlier findings in the present and other cohorts, which have shown associations between exposure to adverse physical working conditions and common mental disorders,${ }^{16}$ disability retirement due to mental disorders, ${ }^{20}$ purchases of sleeping pills ${ }^{19}$ and perceived mental strain. ${ }^{21}$

\section{Methodological considerations}

Certain limitations need to be acknowledged. First, because of the relatively long interval between the two working conditions measurements, this study could have underestimated the effect of changing working conditions on subsequent medication. Moreover, working conditions could have changed several times during the follow-up; this could have resulted in more conservative effect sizes.

Second, we were unable to assess the magnitude of change in working conditions; the use of these crude measures only assessed whether a participant had moved from one category to another. Furthermore, we did not have information about the prior duration of exposure to adverse working conditions. The use of thresholds may

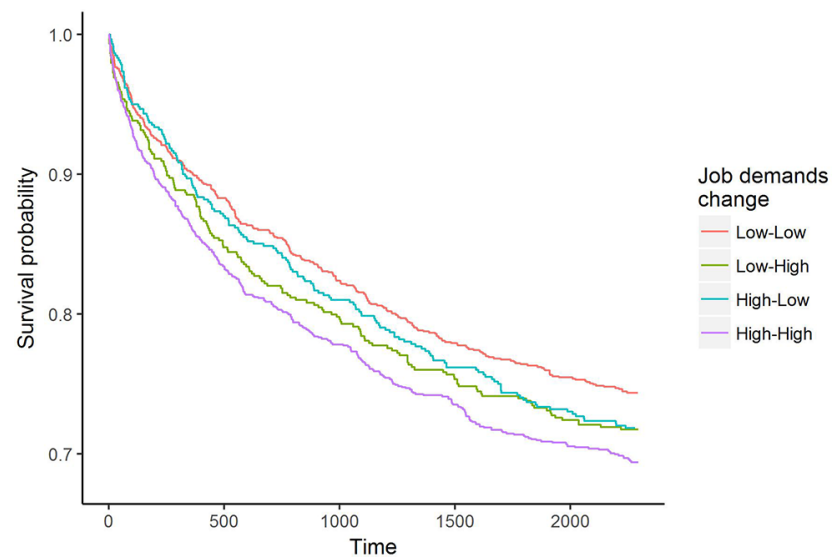

Figure 2 Survival curves for any psychotropic medication by changes in job demands.

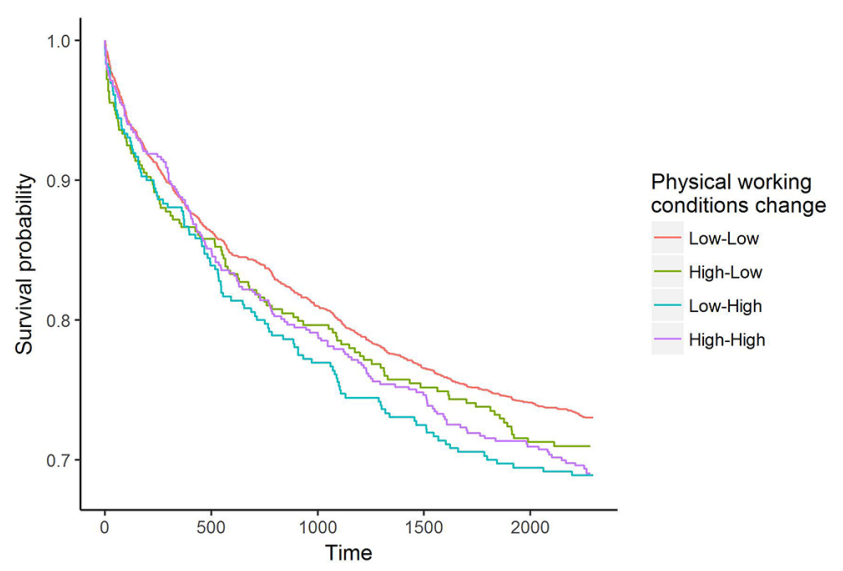

Figure 3 Survival curves for any psychotropic medication by changes in physical working conditions.

have led to underestimates of true effects of changing working conditions. ${ }^{5}$

Third, we did not have information about clinical indication the examined medication was prescribed for. Even if psychotropic medication is a recommended treatment for a number of mental disorders and prescription data derived from official registers can therefore be considered as a proxy for mental disorders requiring treatment, these medications are prescribed also for other conditions. On the other hand, it has been shown that mental disorders are underdiagnosed and undertreated. ${ }^{39}$

Fourth, we did not have information about the discontinuation and the pattern of use of psychotropic medication. Even if a participant had purchased the prescribed medication from the pharmacy, they could have discontinued the use. Discontinuation of psychotropic drugs can lead to different meanings: the discontinuation of antidepressants can be associated with either side effects or lack of follow-up controls, whereas sporadic use of anxiolytics and hypnotics can be due to temporary discomfort. Unfortunately we had no information about the pattern of use of the prescribed medication, that is, whether the medication was used sporadically or continuously.

Fifth, participants who left employment between phase 1 and phase 2 were not included in the study. It has been suggested that the age-related health selection may result in a more resilient older worker population. ${ }^{37} \mathrm{~A}$ healthy worker effect may thus have led to underestimation of the associations.

Finally, even if the data consisted of a broad range of both manual and non-manual occupations, the study population was not a representative sample of the total working population. Because the Finnish public sector workforce is female dominated, women were over-represented also in this sample. Moreover, the present sample consisted only of ageing employees with stable and secure long-term employment and working in the capital city. Therefore, the results may be generalisable, with caution, to the Finnish municipal sector, but might not be generalisable to other age groups, cohorts and industries.

Despite these limitations, the present study has a number of strengths. The main strengths are the use of 


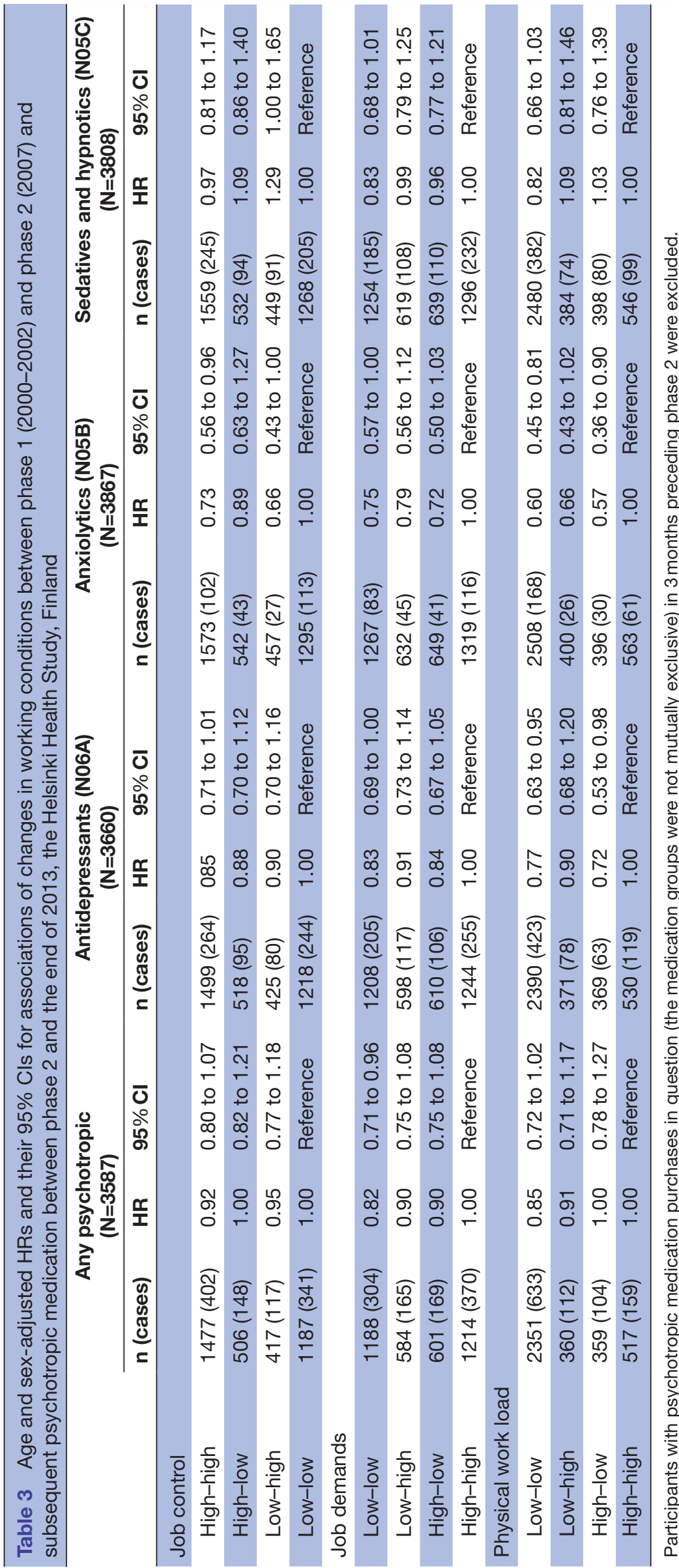


prospective design which enabled us to examine changes in working conditions, data derived from a well-characterised occupational cohort, minor attrition, deterministic linkage to administrative medication records and an ability to examine changes in both psychosocial and physical working conditions. Psychotropic medication data were based on a physician's prescription and covered virtually all reimbursed psychotropic prescriptions for the analytic sample. The use of register-based medication data allowed us to remove the prevalent cases and helped avoid the problems related to use of self-report measures such as recall and common method bias. Extensive non-response analyses were available and showed only small non-participation bias. We were able to adjust for a number of important covariates such as health behaviours and obesity.

\section{CONCLUSION}

To conclude, this study showed that established psychosocial risk factors such as repeated exposure to high job demands and low control are associated with subsequent psychotropic medication in midlife and older employees. Furthermore, the results also showed that repeated and increased exposure to adverse physical working conditions may contribute to subsequent psychotropic medication. Identification of these potentially modifiable risk factors implies possibilities for prevention. ${ }^{40}$ Theory-based, organisationally focused interventions to tackle adverse working conditions might be beneficial. Evidence for this is emerging. An intervention study in Canadian hospitals showed an intervention to reduce work stress was able to produce beneficial long-term effects on hospital employees' emotional well-being, in particular through reducing professional burn-out. ${ }^{41}$ However, well-designed randomised controlled trials with reliable and valid objective indicators of working conditions are needed to reliably test whether intentional workplace interventions can prevent employee mental ill-health.

Twitter@AKouvonen@helsinkiuni

Contributors AK directed the implementation of the study, led all aspects of the work, and drafted the article. AK and OP performed the data analysis. TL, EL, $\mathrm{OP}$ and $\mathrm{OR}$ contributed to acquisition of data. MM, TL, OP, EL and OR contributed to designing the study's analytic strategy, interpreting findings, reviewing the article and revising it critically for important intellectual content. All authors jointly designed and conceptualised the study and approved the manuscript's submission for publication.

Funding This work was supported by the Finnish Work Environment Fund (grant 112231), the Academy of Finland (grants 1129225, 1257362 and 1294514) and the University of Helsinki. AK was supported by the Economic and Social Research Council (ESRC) (grant ES/L007509/1). MM was supported by the Finnish Work Environment Fund (grant 115182) and the Juho Vainio Foundation. TL was supported by the Academy of Finland (grant 287488).

Competing interests None declared.

Ethics approval The Ethics Committees of the Department of Public Health, University of Helsinki, and the health authorities of the City of Helsinki.

Provenance and peer review Not commissioned; externally peer reviewed.

Data sharing statement No additional data available.
Open Access This is an Open Access article distributed in accordance with the Creative Commons Attribution Non Commercial (CC BY-NC 4.0) license, which permits others to distribute, remix, adapt, build upon this work non-commercially, and license their derivative works on different terms, provided the original work is properly cited and the use is non-commercial. See: http://creativecommons.org/ licenses/by-nc/4.0/

C Article author(s) (or their employer(s) unless otherwise stated in the text of the article) 2017. All rights reserved. No commercial use is permitted unless otherwise expressly granted.

\section{REFERENCES}

1. OECD. Sick on the Job? Myths and Realities about Mental Health and Work. 2011. 10.1787/9789264124523-en.

2. LaMontagne AD, Martin A, Page KM, et al. Workplace mental health: developing an integrated intervention approach. BMC Psychiatry 2014;14:131.

3. Stansfeld S, Candy B. Psychosocial work environment and mental health--a meta-analytic review. Scand J Work Environ Health 2006;32:443-62.

4. Nieuwenhuijsen K, Bruinvels D, Frings-Dresen M. Psychosocial work environment and stress-related disorders, a systematic review. Occup Med 2010;60:277-86.

5. Smith PM, Bielecky A. The impact of changes in job strain and its components on the risk of depression. Am J Public Health 2012;102:352-8.

6. Traweger C, Kinzl JF, Traweger-Ravanelli B, et al. Psychosocial factors at the workplace--do they affect substance use? Evidence from the Tyrolean workplace study. Pharmacoepidemiol Drug Saf 2004;13:399-403.

7. Ngoundo-Mbongue TB, Niezborala M, Sulem P, et al. Psychoactive drug consumption: performance-enhancing behaviour and pharmacodependence in workers. Pharmacoepidemiol Drug Saf 2005;14:81-9.

8. Kolstad HA, Hansen AM, Kærgaard A, et al. Job strain and the risk of depression: is reporting biased? Am J Epidemiol 2011;173:94-102.

9. Magnusson Hanson LL, Madsen IE, Westerlund $\mathrm{H}$, et al. Antidepressant use and associations with psychosocial work characteristics. A comparative study of Swedish and Danish gainfully employed. J Affect Disord 2013;149:38-45.

10. Thielen K, Nygaard E, Rugulies R, et al. Job stress and the use of antidepressant medicine: a 3.5-year follow-up study among Danish employees. Occup Environ Med 2011;68:205-10.

11. Virtanen M, Honkonen T, Kivimäki M, et al. Work stress, mental health and antidepressant medication findings from the Health 2000 Study. $J$ Affect Disord 2007;98:189-97.

12. d'Errico A, Cardano M, Landriscina T, et al. Workplace stress and prescription of antidepressant medications: a prospective study on a sample of Italian workers. Int Arch Occup Environ Health 2011;84:413-24.

13. Bonde JP, Munch-Hansen T, Wieclaw J, et al. Psychosocial work environment and antidepressant medication: a prospective cohort study. BMC Public Health 2009;9:262.

14. Lavigne E, Bourbonnais R. Psychosocial work environment, interpersonal violence at work and psychotropic drug use among correctional officers. Int J Law Psychiatry 2010;33:122-9.

15. Stansfeld SA, Fuhrer R, Shipley MJ, et al. Work characteristics predict psychiatric disorder: prospective results from the Whitehall II Study. Occup Environ Med 1999;56:302-7.

16. Kouvonen A, Mänty M, Lallukka T, et al. Changes in psychosocial and physical working conditions and common mental disorders. Eur J Public Health 2016:458-63. ckw019. doi.

17. Bentley RJ, Kavanagh A, Krnjacki L, et al. A longitudinal analysis of changes in job control and mental health. Am J Epidemiol 2015;182:328-34.

18. Strazdins L, D'Souza RM, Clements M, et al. Could better jobs improve mental health? A prospective study of change in work conditions and mental health in mid-aged adults. J Epidemiol Community Health 2011;65:529-34.

19. Laaksonen M, Lallukka T, Lahelma E, et al. Working conditions and psychotropic medication: a prospective cohort study. Soc Psychiatry Psychiatr Epidemiol 2012;47:663-70.

20. Lahelma E, Laaksonen M, Lallukka T, et al. Working conditions as risk factors for disability retirement: a longitudinal register linkage study. BMC Public Health 2012;12:309.

21. Neupane S, Virtanen P, Luukkaala T, et al. A four-year follow-up study of physical working conditions and perceived mental and physical strain among food industry workers. Appl Ergon 2014;45:586-91. 
22. Woo JM, Postolache TT. The impact of work environment on mood disorders and suicide: evidence and implications. Int J Disabil Hum Dev 2008;7:185-200.

23. Melamed S, Luz J, Green MS. Noise exposure, noise annoyance and their relation to psychological distress, accident and sickness absence among blue-collar workers--the Cordis Study. Isr J Med Sci 1992;28:629-35.

24. Lahelma $E$, Aittomäki $A$, Laaksonen $M$, et al. Cohort profile: the Helsinki Health Study. Int J Epidemiol 2013;42:722-30.

25. Laaksonen M, Aittomäki A, Lallukka T, et al. Register-based study among employees showed small nonparticipation bias in health surveys and check-ups. J Clin Epidemiol 2008;61:900-6.

26. Karasek R, Brisson C, Kawakami N, et al. The Job Content Questionnaire (JCQ): an instrument for internationally comparative assessments of psychosocial job characteristics. J Occup Health Psychol 1998;3:322-55

27. Rugulies R, Bültmann U, Aust B, et al. Psychosocial work environment and incidence of severe depressive symptoms: prospective findings from a 5-year follow-up of the Danish work environment cohort study. Am J Epidemiol 2006;163:877-87.

28. Piirainen $\mathrm{H}$, Hirvonen $\mathrm{M}$, Elo AL. The work and Health interview study 2003. Basic report. Helsinki 2003.

29. Laaksonen M, Pitkäniemi J, Rahkonen O, et al. Work arrangements, physical working conditions, and psychosocial working conditions as risk factors for sickness absence: Bayesian analysis of prospective data. Ann Epidemiol 2010;20:332-8.

30. Saastamoinen P, Laaksonen M, Lahelma E, et al. Changes in working conditions and subsequent sickness absence. Scand J Work Environ Health 2014;40:82-8.

31. WHO Collaborating Centre for Drug Statistics Methodology. Guidelines for ATC classification and DDD assignment 2014. Oslo, 2013.

32. Tsuang MT, Bar JL, Stone WS, et al. Gene-environment interactions in mental disorders. World Psychiatry 2004;3:73-83.
33. Kivimäki M, Vahtera J, Kawachi I, et al. Psychosocial work environment as a risk factor for absence with a psychiatric diagnosis: an instrumental-variables analysis. Am J Epidemiol 2010;172:167-72.

34. DeSanto lennaco J, Cullen MR, Cantley L, et al. Effects of externally rated job demand and control on depression diagnosis claims in an industrial cohort. Am J Epidemiol 2010;171:303-11.

35. Joensuu $M$, Väänänen $A$, Koskinen $A$, et al. Psychosocial work environment and hospital admissions due to mental disorders: a 15-year prospective study of industrial employees. J Affect Disord 2010;124:118-25.

36. Ahola K, Honkonen T, Kivimäki M, et al. Contribution of burnout to the association between job strain and depression: the health 2000 study. J Occup Environ Med 2006;48:1023-30.

37. Stansfeld SA, Shipley MJ, Head J, et al. Repeated job strain and the risk of depression: longitudinal analyses from the Whitehall II study. Am J Public Health 2012;102:2360-6.

38. Halonen JI, Lallukka T, Pentti J, et al. Change in job strain as a predictor of change in insomnia symptoms: analyzing observational data as a non-randomized pseudo-trial. Sleep 2016

39. Demyttenaere K, Bruffaerts R, Posada-Villa J, et al. Prevalence, severity, and unmet need for treatment of mental disorders in the World Health Organization World Mental Health Surveys. JAMA 2004;291:2581-90.

40. LaMontagne AD, Krnjacki L, Kavanagh AM, et al. Psychosocial working conditions in a representative sample of working Australians 2001-2008: an analysis of changes in inequalities over time. Occup Environ Med 2013;70:639-47.

41. Bourbonnais R, Brisson C, Vézina M. Long-term effects of an intervention on psychosocial work factors among healthcare professionals in a hospital setting. Occup Environ Med 2011;68:479-86. 


\section{Correction: Changes in psychosocial and physical working conditions and psychotropic medication in ageing public sector employees: a record-linkage follow-up study}

Kouvonen A, Mänty M, Lallukka T, et al. Changes in psychosocial and physical working conditions and psychotropic medication in ageing public sector employees: a record-linkage follow-up study. BMJ Open 2017;7:e015573. doi: 10.1136/ bmjopen-2016-015573.

This article was previously published with some errors.

In review of their article the authors found an error in the equation of their measurement of physical work load. In factor analysis, the items indicating physical work load were loaded on Factor one and not on Factor two, as they had erroneously interpreted earlier (Factor two was hazardous exposures).

This error is corrected by re-running all analyses using the correct factor (physical work load). The authors re-conducted the analyses and found only minor differences compared with the original figures given, and it was also found that the error did not alter the conclusions drawn.

The following corrections should be incorporated into any future analysis of the original article:

In Results section, under Abstract, Age and sex-adjusted HR varied from 1.18 to 1.54, instead of 1.66. In addition, the last sentence of the Results in Abstract (Decreased physical work load was associated with lower risk of antidepressant and anxiolytic medications) should be deleted.

In Results section, under the main text, the following should be corrected:

Paragraph 2: :"The association between repeated high physical work load and any psychotropic medication was also statistically significant (HR=1.27, 95\% CI: 1.08 to 1.49)." rather than "The association between repeated high physical work load and any psychotropic medication was marginally statistically significant ( $\mathrm{HR}=1.17,95 \%$ CI: 0.98 to 1.39$). "$

Paragraph 3: "repeated high physical work load HR=1.54 (95\% CI: 1.15 to 2.06)" instead of "HR=1.66 (95\% CI: 1.24 to 2.23)." In addition, "Increased job control and physical work load were associated with subsequent sedative and hypnotic medication." should read "Increased job control was associated with subsequent sedative and hypnotic medication."

Paragraph 4: The last sentence "Compared with repeatedly high physical work load, decreased physical work load was associated with a lower risk of subsequent antidepressant and anxiolytic medication" should be deleted.

In Discussion, paragraph 6 should have HR=1.54 instead of $\mathrm{HR}=1.66$.

The review led also the three tables, figure 3 and online appendix 2 to be slightly revised. The revised tables are available with this article as tables 1, 2 and 3, figure 3 , and appendix 2. The revised figures in tables have been highlighted in red. 
Table 1 Distribution of demographics (Phase 1; 2000-2002), working conditions (Phase 1 - Phase 2; 2007) and any psychotropic medication* between Phase 2 and 2013, the Helsinki Health Study, Finland (\%) $(n=3587)$

\begin{tabular}{|c|c|c|c|}
\hline & $\begin{array}{l}\text { No medication } N \\
(\%)\end{array}$ & Medication N (\%) & Mean DDDs (SD)† \\
\hline \multicolumn{4}{|l|}{ Sex } \\
\hline Women & $2034(71)$ & 847 (29) & $496.0(773.3)$ \\
\hline Men & $545(77)$ & $161(23)$ & $487.1(793.0)$ \\
\hline \multicolumn{4}{|l|}{ Age } \\
\hline 40 & $632(72)$ & 247 (28) & 587.5 (949.9) \\
\hline 45 & $636(68)$ & $298(32)$ & $537.6(788.6)$ \\
\hline 50 & $664(72)$ & $259(28)$ & $429.5(660.0)$ \\
\hline 55 & $627(76)$ & $196(24)$ & $391.2(627.2)$ \\
\hline 60 & $20(71)$ & $8(29)$ & $662.1(818.6)$ \\
\hline \multicolumn{4}{|l|}{ Job control } \\
\hline High-High & $1075(73)$ & $402(27)$ & $453.2(749.3)$ \\
\hline High-Low & $358(71)$ & $148(29)$ & $458.3(761.1)$ \\
\hline Low-High & $300(72)$ & $117(28)$ & 541.5 (793.9) \\
\hline Low-Low & $846(71)$ & 341 (29) & $543.1(806.6)$ \\
\hline \multicolumn{4}{|l|}{ Job demands } \\
\hline Low-Low & $884(74)$ & $304(26)$ & $411.6(647.4)$ \\
\hline Low-High & 419 (72) & $165(28)$ & $476.1(716.0)$ \\
\hline High-Low & $432(72)$ & $169(28)$ & $463.7(694.2)$ \\
\hline High-High & $844(70)$ & $370(30)$ & $585.1(915.3)$ \\
\hline \multicolumn{4}{|c|}{ Physical work load } \\
\hline Low-Low & $1763(73)$ & $644(27)$ & $465.4(728.0)$ \\
\hline Low-High & $222(70)$ & $93(30)$ & $539.6(798.4)$ \\
\hline High-Low & $222(71)$ & $86(29)$ & 588.1 (997.3) \\
\hline High-High & $382(67)$ & $185(33)$ & $530.0(810.5)$ \\
\hline
\end{tabular}

*Participants with psychotropic medication purchases in 3 months preceding Phase 2 were excluded. †Mean of defined daily doses (DDDs) and their standard deviations (SDs) in those who had psychotropic medication purchases during follow-up.

Table 2 Age and sex adjusted hazard ratios (HRs) and their 95\% confidence intervals (95\% Cls) for associations of changes in working conditions between Phase 1 (2000-2002) and Phase 2 (2007) and subsequent psychotropic medication between Phase 2 and the end of 2013, the Helsinki Health Study, Finland

\begin{tabular}{|c|c|c|c|c|c|c|c|c|c|c|c|c|}
\hline & \multicolumn{3}{|c|}{$\begin{array}{l}\text { Any psychotropic } \\
(n=3587)\end{array}$} & \multicolumn{3}{|c|}{$\begin{array}{l}\text { Antidepressants (N06A) } \\
(\mathrm{n}=3660)\end{array}$} & \multicolumn{3}{|c|}{$\begin{array}{l}\text { Anxiolytics (N05B) } \\
(\mathrm{n}=3867)\end{array}$} & \multicolumn{3}{|c|}{$\begin{array}{l}\text { Sedatives and hypnotics } \\
\text { (N05C) }(n=3808)\end{array}$} \\
\hline & $\begin{array}{l}\mathrm{N} \\
\text { (cases) }\end{array}$ & HR & $95 \% \mathrm{Cl}$ & $\begin{array}{l}\mathbf{N} \\
\text { (cases) }\end{array}$ & HR & $95 \% \mathrm{Cl}$ & $\begin{array}{l}\mathbf{N} \\
\text { (cases) }\end{array}$ & HR & $95 \% \mathrm{Cl}$ & $\begin{array}{l}\mathbf{N} \\
\text { (cases) }\end{array}$ & HR & $95 \% \mathrm{Cl}$ \\
\hline \multicolumn{13}{|l|}{ Job control } \\
\hline High-High & $\begin{array}{l}1477 \\
(402)\end{array}$ & 1.00 & Reference & $\begin{array}{l}1499 \\
(264)\end{array}$ & 1.00 & Reference & $\begin{array}{l}1573 \\
(102)\end{array}$ & 1.00 & Reference & $\begin{array}{l}1559 \\
(245)\end{array}$ & 1.00 & Reference \\
\hline High-Low & $\begin{array}{l}506 \\
(148)\end{array}$ & 1.08 & $\begin{array}{l}0.90 \text { to } \\
1.31\end{array}$ & $\begin{array}{l}518 \\
(95)\end{array}$ & 1.04 & $\begin{array}{l}0.82 \text { to } \\
1.32\end{array}$ & $\begin{array}{l}542 \\
(43)\end{array}$ & 1.22 & $\begin{array}{l}0.86 \text { to } \\
1.74\end{array}$ & $\begin{array}{l}532 \\
(94)\end{array}$ & 1.13 & $\begin{array}{l}0.89 \text { to } \\
1.43\end{array}$ \\
\hline Low-High & $\begin{array}{l}417 \\
(117)\end{array}$ & 1.03 & $\begin{array}{l}0.84 \text { to } \\
1.27\end{array}$ & $\begin{array}{l}425 \\
(80)\end{array}$ & 1.06 & $\begin{array}{l}0.83 \text { to } \\
1.36\end{array}$ & $\begin{array}{l}457 \\
(27)\end{array}$ & 0.90 & $\begin{array}{l}0.59 \text { to } \\
1.38\end{array}$ & $\begin{array}{l}449 \\
(91)\end{array}$ & 1.33 & $\begin{array}{l}1.04 \text { to } \\
1.69\end{array}$ \\
\hline Low-Low & $\begin{array}{l}1187 \\
(341)\end{array}$ & 1.08 & $\begin{array}{l}0.94 \text { to } \\
1.25\end{array}$ & $\begin{array}{l}1218 \\
(244)\end{array}$ & 1.18 & $\begin{array}{l}0.99 \text { to } \\
1.41\end{array}$ & $\begin{array}{l}1295 \\
(113)\end{array}$ & 1.37 & $\begin{array}{l}1.05 \text { to } \\
1.79\end{array}$ & $\begin{array}{l}1268 \\
(205)\end{array}$ & 1.03 & $\begin{array}{l}0.86 \text { to } \\
1.24\end{array}$ \\
\hline
\end{tabular}




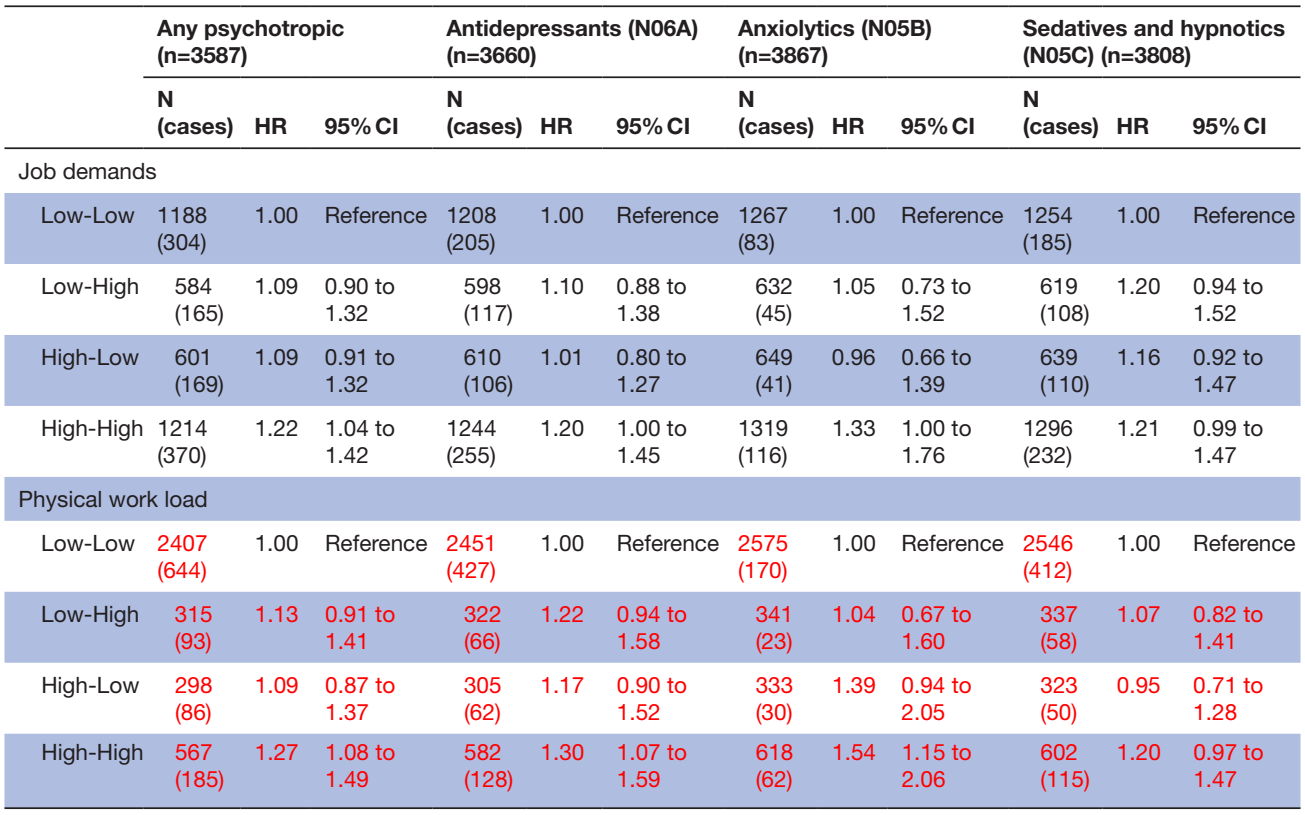

Participants with psychotropic medication purchases in question (the medication groups were not mutually exclusive) in 3 months preceding Phase 2 were excluded.

Table 3 Age and sex adjusted hazard ratios (HRs) and their 95\% confidence intervals (95\% Cls) for associations of changes in working conditions between Phase 1 (2000-2002) and Phase 2 (2007) and subsequent psychotropic medication between Phase 2 and the end of 2013, the Helsinki Health Study, Finland

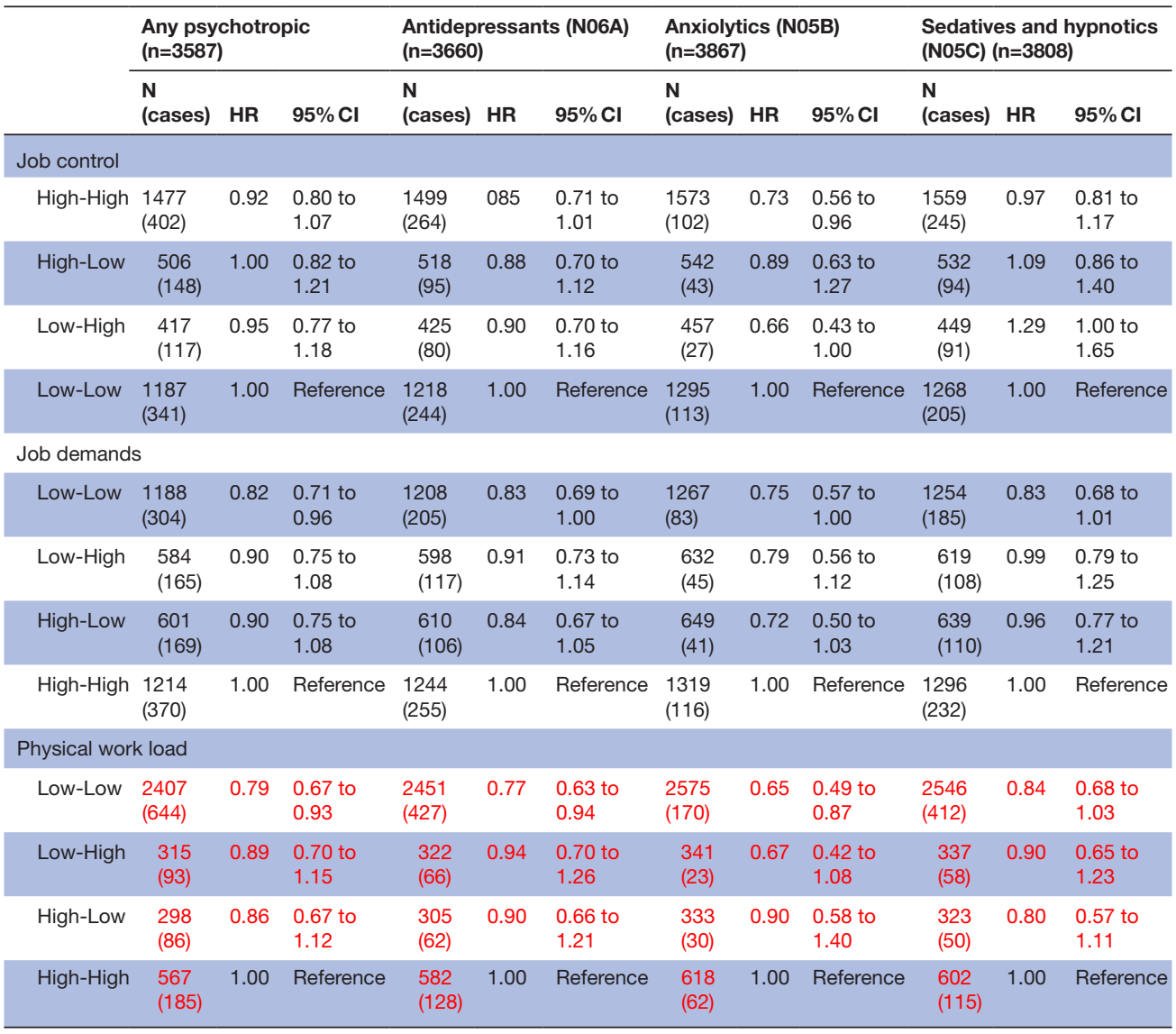




\begin{tabular}{|c|c|c|c|c|c|c|c|c|c|c|c|}
\hline \multicolumn{3}{|c|}{$\begin{array}{l}\text { Any psychotropic } \\
(\mathrm{n}=3587)\end{array}$} & \multicolumn{3}{|c|}{$\begin{array}{l}\text { Antidepressants (N06A) } \\
(\mathrm{n}=3660)\end{array}$} & \multicolumn{3}{|c|}{$\begin{array}{l}\text { Anxiolytics (N05B) } \\
(n=3867)\end{array}$} & \multicolumn{3}{|c|}{$\begin{array}{l}\text { Sedatives and hypnotics } \\
\text { (N05C) }(n=3808)\end{array}$} \\
\hline $\begin{array}{l}\mathrm{N} \\
\text { (cases) }\end{array}$ & HR & $95 \% \mathrm{Cl}$ & $\begin{array}{l}\mathrm{N} \\
\text { (cases) }\end{array}$ & HR & $95 \% \mathrm{Cl}$ & $\begin{array}{l}\mathrm{N} \\
\text { (cases) }\end{array}$ & HR & $95 \% \mathrm{Cl}$ & $\begin{array}{l}\mathrm{N} \\
\text { (cases) }\end{array}$ & HR & $95 \% \mathrm{Cl}$ \\
\hline
\end{tabular}

Participants with psychotropic medication purchases in question (the medication groups were not mutually exclusive) in 3 months preceding Phase 2 were excluded.

Figure 3 Survival curves for any psychotropic medication by changes in physical working conditions.

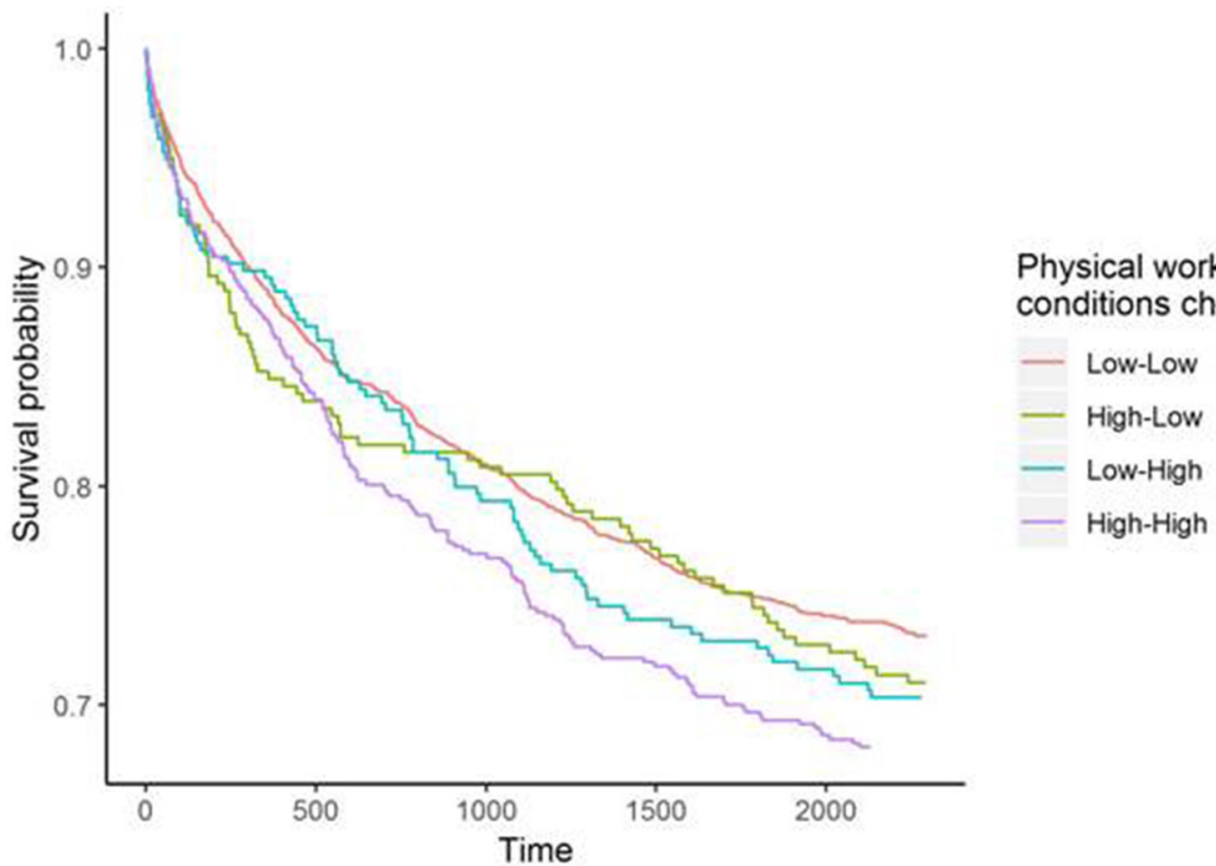

Appendix 2 Physical working conditions - age

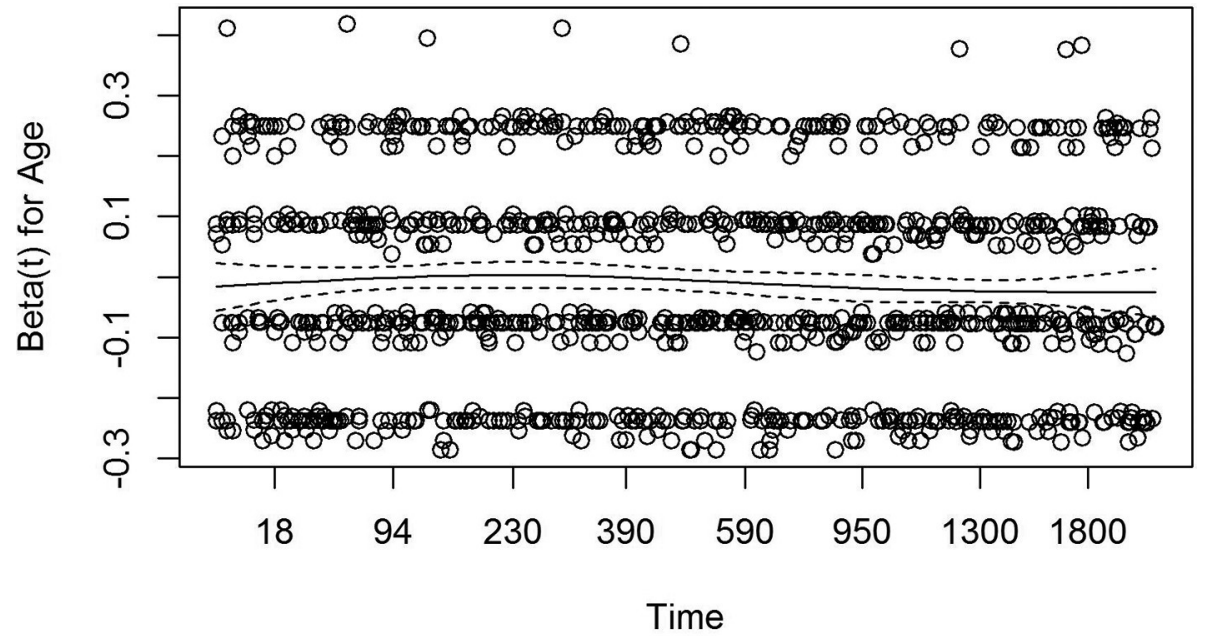




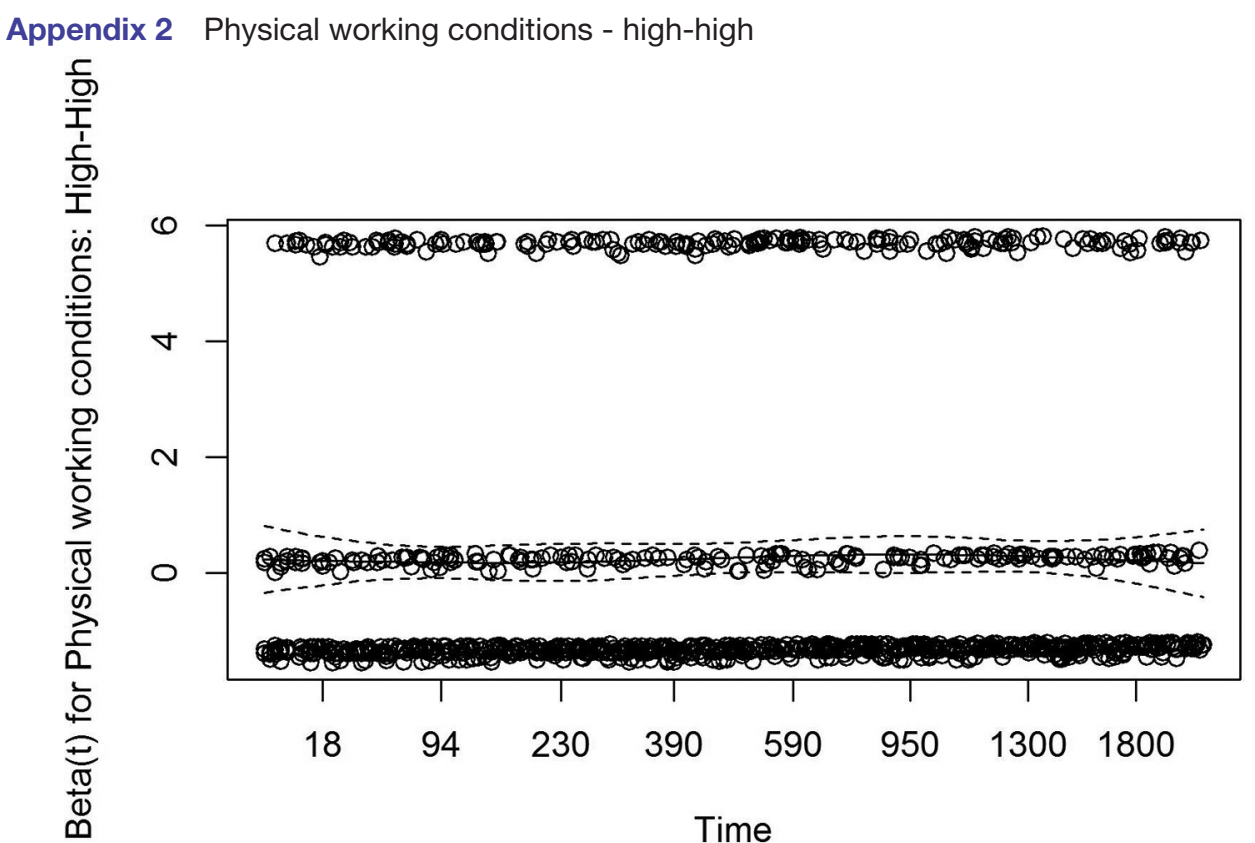

Appendix 2 Physical working conditions - high-low

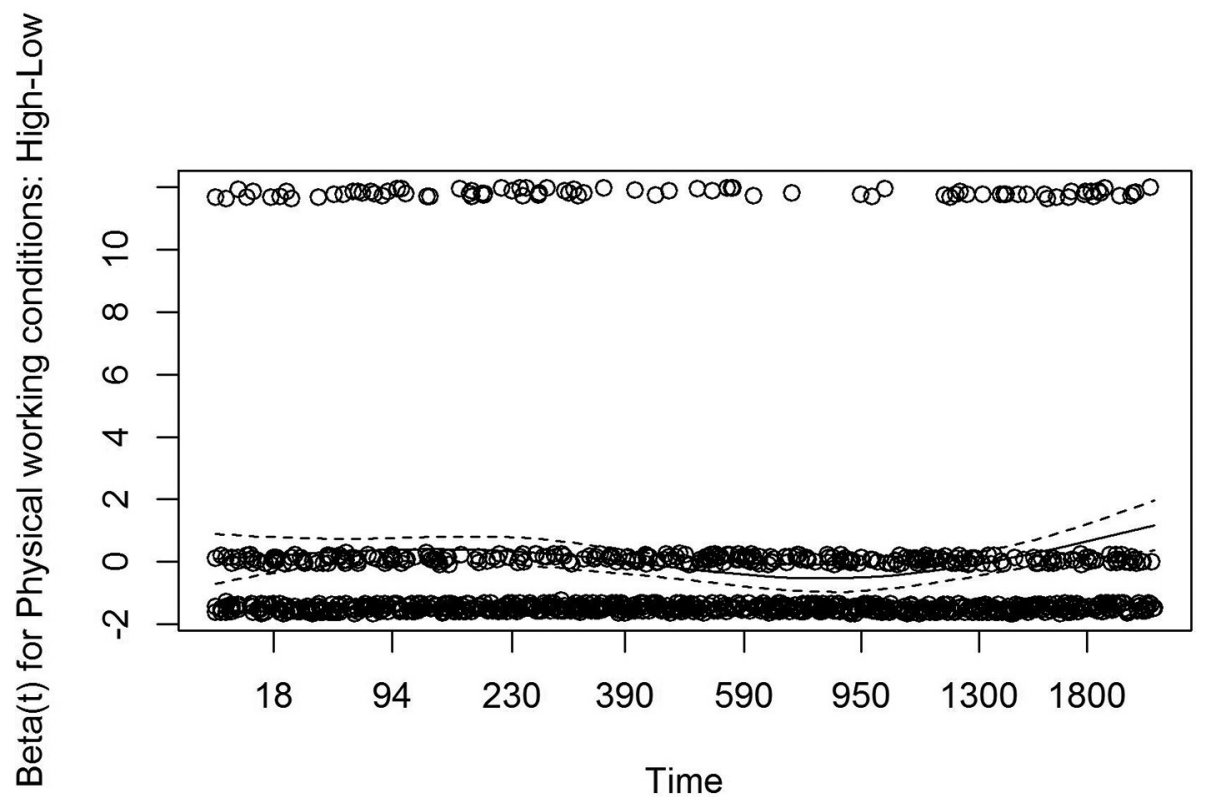


Appendix 2 Physical working conditions - low-high

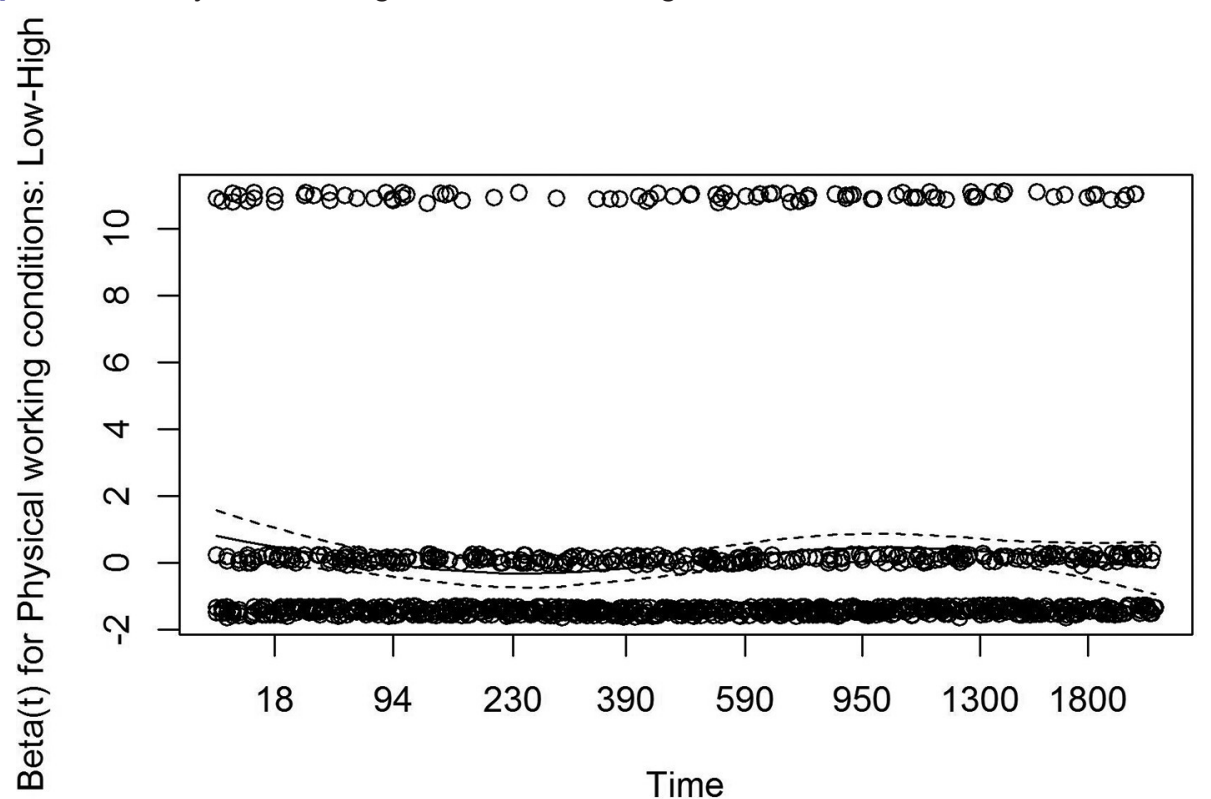

Appendix 2 Physical working conditions - sex

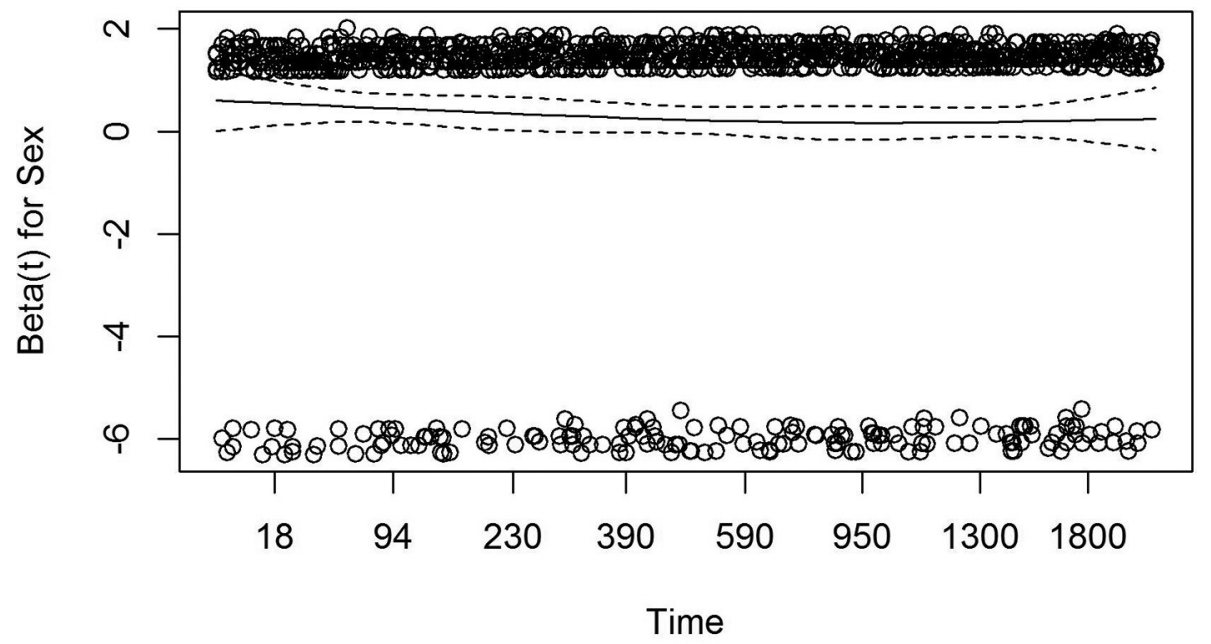

Open access This is an open access article distributed in accordance with the Creative Commons Attribution Non Commercial (CC BY-NC 4.0) license, which permits others to distribute, remix, adapt, build upon this work non-commercially, and license their derivative works on different terms, provided the original work is properly cited, appropriate credit is given, any changes made indicated, and the use is non-commercial. See: http://creativecommons.org/licenses/by-nc/4.0/.

(c) Author(s) (or their employer(s)) 2019. Re-use permitted under CC BY-NC. No commercial re-use. See rights and permissions. Published by BMJ.

BMJ Open 2019;9:e015573corr1. doi:10.1136/bmjopen-2016-015573corr1

Check for updates 